\title{
Filhas que cuidam de pais/mães com provável/possível Doença de Alzheimer
}

\author{
Deusivânia Vieira da Silva Falcão \\ Universidade de São Paulo \\ Julia Sursis Nobre Ferro Bucher-Maluschke
}

Universidade de Brasília/Universidade de Fortaleza

\begin{abstract}
Resumo
Este estudo investigou 32 filhas cuidadoras de pais/mães com provável/possível doença de Alzheimer (DA). Objetivou avaliar as reações iniciais delas diante do diagnóstico; as concepções sobre as características pessoais dos portadores antes e após a DA; os principais motivos que levaram a cuidar de seus genitores e quais os sentimentos diante do papel exercido. Elaborou-se uma entrevista que foi gravada, transcrita e analisada segundo a técnica de Bardin (1977/2000). Constatou-se que elas apresentaram uma reação inicial desfavorável diante da doença. Os motivos mais apontados para exercerem o papel, foram os sentimentos de obrigação filial e gratidão. No geral, elas não se sentiam bem executando essa tarefa. Entrementes, benefícios foram apontados por algumas, tais como crescimento pessoal. Conclui-se que a atividade de cuidar é heterogênea, multifacetada e as avaliações subjetivas das entrevistadas eram influenciadas por crenças, regras familiares, relacionamento com o idoso e percepções acerca da velhice e do cuidado.
\end{abstract}

Palavras-chave: cuidadores; filhas; alzheimer; demência; idosos

\begin{abstract}
Daughters who take care of fathers/mothers with probable/possible Alzheimer's Disease. This study investigated 32 daughters who take care of fathers/mothers with probable/possible Alzheimer's Disease (AD). It focused on evaluating daughters initial reactions facing the diagnosis; their conceptions concerning the personal characteristics of the diseased before and after $\mathrm{AD}$; the main reasons that brought them to be the caregivers, nurses, of their parents and what are the feelings towards the activity role. An interview was elaborated, then recorded, transcribed and analyzed according to Bardin's technique (1977/2000). It was verified that they presented an unfavorable first reaction facing the disease. The most appointed motivations were the feelings of obligation and gratitude. In general, they did not feel at easy executing this duty. Nevertheless benefits as self-growth were appointed by some. It is concluded that the activity of care giving is heterogenic, multiply faced and the subjective evaluations of the interviewed were influenced by religious beliefs, familiar rules, the relationship with the elderly and perceptions of old age and care giving.
\end{abstract}

Keywords: caregivers; daughters; alzheimer; dementia; elderly

$\mathrm{A}$ doença de Alzheimer (DA) é a forma mais comum de demência que acomete a população idosa. O primeiro mais evidente sintoma que emerge em pacientes com essa enfermidade é o déficit de memória episódica anterógrada que se refere à recordação de eventos recentes definidos no tempo e no espaço (Charchat, Nitrini, Caramelli, \& Sameshima, 2001). Devido ao fato de a perda da memória ser comumente associada à velhice, observa-se que os familiares ou os próprios idosos esperam muito tempo para buscar o auxílio de profissionais.

O diagnóstico da doença baseia-se na observação de quadro clínico compatível, na exclusão de outras causas de demência e de distúrbios com impacto sobre o sistema nervoso central. Por meio de exames laboratoriais e de neuroimagem estrutural, observa-se a atrofia da formação hipocampal e do córtex cerebral, de distribuição difusa ou de predomínio em regiões posteriores. Esses pacientes preenchem os critérios diagnósticos da DA provável. O diagnóstico de DA possível, é dado nos casos em que os sujeitos revelam variações na forma de apresentação ou evolução clínica e também naqueles em que outras condições passíveis de produzir demência estejam presentes, porém sem serem consideradas, com base em juízo e experiência clínica responsáveis pelo quadro demencial. Desse modo, o diagnóstico 
definitivo é realizado apenas após exame anatomopatológico (Caramelli \& Barbosa, 2002).

Ocorre ainda que os portadores dessa enfermidade necessitam de auxílio para a realização de várias atividades da vida diária (AVD) e, conseqüentemente, de uma ou mais pessoas que cuidem deles. Trata-se de alguém que realiza as tarefas que o idoso não tem mais possibilidade de executar, as quais vão desde a higiene pessoal até a administração financeira da família. O cuidado pode ser executado pelos familiares, por profissionais e por instituições de saúde. Segundo Santos (2003), é no campo familiar que os indivíduos aprendem e desenvolvem suas práticas de cuidado, bastante influenciadas pelos aspectos socioculturais.

No âmbito da família, a construção do papel de cuidador de um idoso com demência, desenvolve-se à medida que a enfermidade evolui, e os membros do sistema vivenciam a implementação dos cuidados. Nesse cenário, a posição de cuidador geralmente obedece aos seguintes fatores: parentesco (com frequiência maior para os cônjuges e filhas); gênero (destacando-se o feminino); proximidade afetiva e física (considerando quem vive com o paciente); condições financeiras e personalidade dos envolvidos; disponibilidade de tempo ou preparo para lidar com a situação; e expectativa da família de origem em relação a eles, ou seja, como se fossem designados pelos familiares a desenvolverem essa atividade (Cattani \& Girardon-Perlini, 2004; Coen, Swanwick, O’Boyle, \& Coakley, 1997; Falcão, 2006).

Na família, a doença ou a limitação física em uma pessoa provoca mudanças na vida de todos os parentes. É comum a ocorrência de alterações nas funções ou no papel de cada membro familiar; por exemplo, a filha que passa a cuidar da mãe (Ministério da Saúde, 2008). Nesse contexto, a literatura indica que há um envolvimento maior das mulheres no processo de cuidar (Falcão, 2006). De acordo com a Sociedad Española de Geriatría y Gerontología (2005), a maioria das pessoas que cuidam de idosos na Espanha é filha do paciente, está na maturidade, é casada e reside no mesmo domicílio do idoso. Também não possui um trabalho remunerado, não recebe ajuda de outras pessoas, e a rotação familiar de substituição da cuidadora principal por outros membros da família é relativamente baixa. A filha favorita e a única mulher entre os irmãos também se enquadram nesse perfil.

Além de dificuldades de ordem física e psicológica, tais como estresse, apatia, tristeza crônica e depressão, as cuidadoras tendem a enfrentar diversos problemas financeiros (Teel \& Carson, 2003; Winslow, 2003). O desenvolvimento de distúrbios de comportamento do portador é um dos problemas que emergem, com freqüência, durante a evolução da doença. Destarte, a vida da pessoa cuidadora passa a ser influenciada tanto pelos aspectos cognitivos como pelos comportamentais da demência (Robinson, Adkinsson, \& Weinrich, 2001). Muitas delas passam a sair menos de casa, a ter sua vida social restrita e sua rede de suporte social reduzida (Sawatzky \& Fowler-Kerry, 2003).

Em alguns países, como nos Estados Unidos, existe uma política de apoio a estas mulheres, no caso de alguma pessoa idosa vir a depender delas. A jornada de trabalho pode ser reduzida, além de receberem uma ajuda em dinheiro, para suprir os gastos com a assistência prestada ao portador da demência (Lechner \& Neal, 1999). Na realidade brasileira, percebe-se que, em virtude do engajamento cada vez maior no mercado de trabalho, a mulher está cada vez menos disponível para exercer esse papel. Além disso, por diversos fatores de ordem socioeconômica, os núcleos familiares estão menores e, portanto, menos aptos para se dedicarem aos cuidados com seus idosos. Outrossim, a maioria dos sistemas formais de suporte não têm sido capazes de substituir a família com eficiência.

Partindo-se dessas informações, a presente pesquisa objetivou investigar, na perspectiva de filhas cuidadoras de pais/ mães com provável/possível DA, as reações iniciais delas diante do diagnóstico dessa enfermidade; as principais atividades de cuidado desenvolvidas; as concepções sobre as características pessoais dos portadores antes e após a DA; a vida pessoal delas antes e após a enfermidade; os principais motivos que as levaram a cuidar de seus genitores e quais os sentimentos vivenciados diante do exercício dessa tarefa. Acredita-se que este estudo poderá refletir propostas de intervenções para os profissionais, órgãos governamentais e não-governamentais envolvidos com a temática em pauta.

\section{Método}

\section{Local do estudo}

A pesquisa foi realizada no Centro de Referência em Assistência à Saúde do Idoso e Portadores da Doença de Alzheimer, que funciona no Centro de Medicina do Idoso (CMI), situado no Hospital Universitário de Brasília (HUB), Distrito Federal.

\section{Participantes}

Participaram do estudo 32 mulheres cuidadoras, com idades variando entre 35 e 64 anos $(M=51,38 ; D P=7,17)$, sendo que 26 delas estavam na meia-idade. Constatou-se também que 15 eram casadas, 10 solteiras, 4 separadas/divorciadas, e 3 viúvas. Dentre as casadas, a idade média do tempo de casamento era de 26 anos. Verificou-se que $44 \%$ delas eram primogênitas, $31 \%$ filhas sanduíches (do meio) e $25 \%$ caçulas. A maioria possuía filhos (81\%), sendo a média de idade deles de 25 anos. Também, $75 \%$ delas não tinham netos, $70 \%$ professavam a religião católica, 50\% tinham nível superior e 60\% estavam aposentadas, exercendo a profissão do lar. A renda salarial delas variou de 1 a 51 salários mínimos ( $M=5$ salários). Das 13 cuidadoras que trabalhavam fora do lar, 10 exerciam suas funções em tempo parcial. Cerca de $60 \%$ delas não contavam com a ajuda de outros membros familiares ou cuidadores formais para dividir igualitariamente a tarefa de cuidar dos portadores.

Como critério de inclusão, as cuidadoras deveriam: (a) ser filha da pessoa idosa com provável ou possível diagnóstico de DA; (b) ser a principal responsável pelos cuidados com a mãe/o pai portador(a) e; (c) morar na mesma residência do(a) idoso(a).

Por meio das informações do prontuário médico, dos resultados do Mini-Mental State Examination (aplicado por 
profissionais do CMI) e das entrevistas realizadas pela equipe de Psicologia, destaca-se que 65\% dos idosos (6 homens e 26 mulheres) portadores da DA apresentavam características inerentes à fase intermediária. A idade deles variou entre 70-92 $(M=79)$ anos. Verificou-se que 10 eram casados, 4 separados/ divorciados e 18 viúvos. Entre os que estavam casados, a idade média do tempo de casamento era de 50 anos. Também, 66\% possuíam Ensino Básico, 78\% professavam a religião católica e $60 \%$ exerceram a profissão do lar antes da DA. A renda salarial deles variou de 1 a 33 salários mínimos ( $M=3$ salários). Em três casos, as filhas moravam na casa dos pais e, nos demais casos, os pais idosos residiam na casa delas. A média do tempo de moradia conjunta era de 14 anos.

\section{Instrumento e procedimentos}

$\mathrm{O}$ instrumento utilizado consistiu numa entrevista com roteiro semi-estruturado contemplando os objetivos do estudo. Elaborou-se o roteiro a partir da revisão bibliográfica e de uma pesquisa piloto realizada com cinco filhas. O projeto foi aprovado pelo Comitê de Ética em Pesquisa da Faculdade de Medicina da Universidade de Brasília. As participantes foram selecionadas com base nos prontuários de pacientes que haviam sido atendidos pela equipe do Centro de Referência. Após a seleção das participantes, telefonou-se para cada uma, informouse sobre a pesquisa, solicitando-se a presença, junto ao Centro, em horário marcado.

No contato face a face, buscou-se estabelecer um rapport, com o intuito de facilitar a relação entrevistadora/entrevistada, explicando-se, de modo amplo, os objetivos gerais da pesquisa e como esta seria aplicada. Após as explicações, executou-se a leitura conjunta do Termo de Consentimento Livre e Esclarecido, de acordo com a Resolução № 196 do Ministério da Saúde - Conselho Nacional de Saúde -, e da Resolução CFP № 016/200, que versa sobre a realização de pesquisa em Psicologia com seres humanos. A partir da anuência das participantes, explicavam-se os procedimentos do estudo e solicitava-se a assinatura delas no documento. Para resguardar a identidade das pessoas, os nomes apresentados neste trabalho são fictícios. As entrevistas foram realizadas individualmente, utilizando-se o gravador com autorização prévia da respondente e com duração indeterminada.

\section{Análise dos dados}

As entrevistas foram analisadas por meio da técnica de Bardin (1977/2000) e consistiu em três períodos: a pré-análise, a exploração do material e o tratamento dos resultados. Reunindo as entrevistas transcritas, constituiu-se o corpus da pesquisa. Na fase da pré-análise, foi feita uma leitura flutuante. Na exploração do material, obedeceu-se às regras de: (a) exaustividade esgotando-se a totalidade da comunicação, não omitindo nem uma informação; (b) representatividade - representou-se o universo da amostra; (c) homogeneidade - os dados referiram-se ao mesmo tema, foram obtidos por técnicas iguais e aplicadas por indivíduos semelhantes; (d) pertinência - as entrevistas foram adaptadas aos objetivos da pesquisa; e (e) exclusividade - um elemento não foi classificado em mais de uma categoria.

Explorou-se o material, codificando-o em função das regras supracitadas, sendo feita a escolha pela unidade temática e pela unidade de contexto, obtidas através de núcleos de sentido das falas das participantes. Em seguida, as categorias foram definidas e classificadas de acordo com seus conteúdos. O material das entrevistas foi organizado de acordo com um significado comum, expresso em códigos, relacionando-o a uma transformação dos dados brutos do texto, a qual permitiu atingir uma representação do conteúdo. Criaram-se categorias analíticas que permitiram abarcar a totalidade das entrevistas em grandes eixos temáticos. A análise qualitativa da informação codificada favoreceu a verificação das ocorrências de cada categoria, a identificação de subcategorias, e a extração dos trechos das entrevistas correspondentes a elas. Para maiores informações, consultar o Apêndice.

Além do cumprimento dessas etapas, o tratamento dos resultados e as interpretações também abarcaram a freqüência simples das unidades de análise. A ponderação da freqüência de cada unidade traduziu um caráter quantitativo (dimensão; número de falas repetidas, isto é, agrupadas pela semelhança do conteúdo expresso nas verbalizações) e qualitativo (direção, classificação dos conteúdos) dos modelos de comportamento das respondentes, permitindo identificar os temas principais e os alvos de interesses delas. A direção dos conteúdos analisados foi favorável (aspectos positivos das afirmações), desfavorável (aspectos negativos das informações) ou neutra (conteúdo indefinido, vago, indeterminado, indiferente ou imparcial, que não expressava partido nem a favor nem contra). Para Bardin (1977/2000), a análise qualitativa não rejeita toda e qualquer forma de quantificação. Assim, foi realizada uma análise "quali-quanti” das entrevistas. A seguir, serão demonstrados os resultados quantitativos. Posteriormente, durante a discussão, os dados qualitativos serão refletidos a partir das categorias obtidas e de pesquisas desenvolvidas na área da temática em pauta.

\section{Resultados}

Dentre as categorias apresentadas na Tabela 1, observa-se que a mais destacada foi a reação inicial desfavorável à utilização dos recursos da família para lidar com a doença, com 52 unidades de análise (81,3\%).

Na Tabela 2, verifica-se que a categoria mais destacada pelas filhas no que se refere às atividades de cuidado foi controlar/ orientar com 86 unidades de análise (35,7\%).

Na Tabela 3, constata-se que as verbalizações mais ressaltadas pelas filhas a respeito das principais características dos idosos portadores da DA antes da doença foi a de pessoa ativa, com 88 unidades (40,4\%). Após a doença, destacou-se a categoria perdeu a memória (131 unidades; 31\%).

Por meio das entrevistas, verificou-se, ainda, que a maioria das filhas apontava mais de um motivo para cuidar de seus genitores, sendo os principais deles: sentimento de obrigação filial (18 filhas); gratidão (14 filhas); condições socioeconômicas e profissionais (11 filhas); o fato de que sempre exerceu o papel de cuidadora na família, desenvolvendo o que se denomina carreira de cuidados (8 filhas); missão divina (8 filhas); amor (6 filhas); falta de opção (5 filhas); estado civil de solteira (4 filhas); por ser mulher (3 filhas); oportunidade de rever os erros 
Tabela 1

Tipos de reação inicial das filhas cuidadoras e respectivas freqüências.

\begin{tabular}{lcc}
\hline \multirow{2}{*}{ Tipos de reação inicial } & \multicolumn{2}{c}{$\begin{array}{c}\text { Freqüência de unidades de } \\
\text { análise }\end{array}$} \\
\cline { 2 - 3 } & Absoluta & Percentual \\
\hline $\begin{array}{l}\text { Reação inicial desfavorável à utilização dos } \\
\text { recursos da família para lidar com a doença }\end{array}$ & 52 & 81,3 \\
$\begin{array}{l}\text { Reação inicial neutra } \\
\text { Reação inicial favorável à utilização dos }\end{array}$ & 10 & 15,6 \\
recursos da família para lidar com a doença & 2 & 3,1 \\
\hline Total & 64 & 100 \\
\hline
\end{tabular}

Tabela 2

Principais atividades de cuidado e respectivas freqüencias

\begin{tabular}{|c|c|c|}
\hline \multirow[t]{2}{*}{ Atividades } & \multicolumn{2}{|c|}{$\begin{array}{c}\text { Freqüência de unidades } \\
\text { de análise }\end{array}$} \\
\hline & Absoluta & Percentual \\
\hline \multicolumn{3}{|l|}{ Instrumentais } \\
\hline Controlar/orientar & 86 & 35,7 \\
\hline Cuidar da higiene pessoal & 45 & 18,7 \\
\hline Cuidar da alimentação e da medicação & 35 & 14,5 \\
\hline Passear/realizar caminhadas & 30 & 12,4 \\
\hline Levar ao médico & 25 & 10,4 \\
\hline \multicolumn{3}{|l|}{ Afetivas } \\
\hline Conversar & 12 & 5,0 \\
\hline Dar carinho & 8 & 3,3 \\
\hline Total & 241 & 100 \\
\hline
\end{tabular}

Tabela 3

Principais características pessoais de mães e pais portadores da DA, antes da doença e com ela, na perspectiva das filhas cuidadoras e respectivas freqüências

\begin{tabular}{|c|c|c|}
\hline \multirow[t]{2}{*}{ Características pessoais } & \multicolumn{2}{|c|}{$\begin{array}{c}\text { Freqüência de unidades de } \\
\text { análise }\end{array}$} \\
\hline & Absoluta & Percentual \\
\hline \multicolumn{3}{|l|}{ Antes da doença } \\
\hline Pessoa ativa & 88 & 40,4 \\
\hline Pessoa dominadora & 53 & 24,3 \\
\hline Amoroso(a)/prestativo(a) & 30 & 13,7 \\
\hline Estressado(a)/explosivo(a) & 27 & 12,4 \\
\hline Quieto(a)/calmo(a) & 20 & 9,2 \\
\hline Total & 218 & 100 \\
\hline \multicolumn{3}{|l|}{ Com a doença } \\
\hline Perdeu a memória & 131 & 31,0 \\
\hline Desorientado(a) & 95 & 22,5 \\
\hline Perdeu a autonomia & 36 & 8,5 \\
\hline Inquieto e caminha compulsivamente & 32 & 7,6 \\
\hline Agressivo(a) (verbalmente/fisicamente) & 30 & 7,0 \\
\hline $\begin{array}{l}\text { Apresenta falas repetitivas e dificulda- } \\
\text { de na comunicação }\end{array}$ & 26 & 6,0 \\
\hline Alucinando/Delirando & 25 & 6,0 \\
\hline Implicante & 20 & 4,8 \\
\hline Apresenta picos de lucidez & 18 & 4,2 \\
\hline Apresenta labilidade emocional & 10 & 2,4 \\
\hline Total & 423 & 100 \\
\hline
\end{tabular}


do passado (3 filhas); características de personalidade (2 filhas); o fato de nunca ter saído de casa (2 filhas); posição que ocupava entre os irmãos (2 filhas).

Na Tabela 4, predominaram as verbalizações que mencionavam o sentimento desfavorável diante do fato de cuidar do portador(a), com 88 unidades de análise (63,3\%).

Tabela 4

Tipos de sentimento das filhas cuidadoras e respectivas freqüências

\begin{tabular}{lrc}
\hline \multirow{2}{*}{\multicolumn{1}{c}{ Tipos de sentimento }} & \multicolumn{2}{c}{$\begin{array}{c}\text { Freqüência de unidades } \\
\text { de análise }\end{array}$} \\
\cline { 2 - 3 } & Absoluta & Percentual \\
\hline Sentimento desfavorável & 88 & 63,3 \\
Sentimento favorável & 45 & 32,4 \\
Sentimento neutro & 6 & 4,3 \\
\hline Total & 139 & 100 \\
\hline
\end{tabular}

Na Tabela 5, constata-se que as filhas cuidadoras tenderam a verbalizar sua vida pessoal antes da doença com aspectos desfavoráveis (81 unidades de análise; 55,1\%). Após a doença, observou-se que a subcategoria vida pessoal com aspectos desfavoráveis continuou sendo destaque, apresentando 125 unidades de análise (72,7\%).

Tabela 5

Aspectos da vida pessoal das filhas cuidadoras antes da doença dos pais e com ela, e suas respectivas freqüencias

\begin{tabular}{lrc}
\hline \multirow{2}{*}{\begin{tabular}{c} 
Aspectos da vida pessoal das \\
\multicolumn{1}{c}{ filhas }
\end{tabular}} & \multicolumn{2}{c}{$\begin{array}{c}\text { Freqüência de unidades } \\
\text { de análise }\end{array}$} \\
\cline { 2 - 3 }$\quad$ Antes da doença & Absoluta & Percentual \\
\hline Com aspectos desfavoráveis & 81 & 55,1 \\
Com aspectos favoráveis & 62 & 42,2 \\
Com aspectos neutros & 4 & 2,7 \\
\hline Total Com a doença & 147 & 100 \\
\hline \multicolumn{1}{c}{$\quad$} & \\
Com aspectos desfavoráveis & 125 & 72,7 \\
Com aspectos favoráveis & 42 & 24,4 \\
Com aspectos neutros & 5 & 2,9 \\
\hline Total & 172 & 100 \\
\hline
\end{tabular}

\section{Discussão}

\section{As reações iniciais das cuidadoras diante do prováv-} el/possível diagnóstico da DA

Ao receber a notícia do provável/possível diagnóstico de DA, a família inicia um processo de culpa, por vezes, devido à não valorização das queixas ou sintomas, à irritação e à falta de paciência do familiar para com o portador (Luders \& Storani, 2005). Assim, podem reagir de maneiras diversas como, por exemplo, choque, rejeição e negação. Muitas dessas reações estão ligadas à vivência da perda da pessoa idosa e do lugar que esta ocupa na família.

Neste estudo, a maioria das filhas cuidadoras destacou a reação inicial desfavorável diante da notícia do provável/ possível diagnóstico da DA. Sentimentos tais como medo, indignação, choro, revolta, culpa e negação, marcaram esse momento que foi vivenciado não somente por elas, mas também pela família extensa. Para ilustrar essa afirmação, apresentam-se os discursos a seguir: "A minha primeira reação foi sentir raiva. Que doença é essa? Como é que eu não tenho mais a minha mãe pra me apoiar? Fiquei meio sem mãe, de repente! [chora]" (Alessandra); "Fiquei anestesiada! Meus irmãos não acreditaram no início, diziam que era invenção, que não era essa doença. Hoje estão vendo que não é brincadeira!” (Bruna).

Semelhantemente, outros pesquisadores (Coelho \& Diniz, 2005; Coelho, Falcão, Campos, \& Vieira, 2006; Luders \& Storani, 2005) destacaram que o diagnóstico e o processo demencial alteram a dinâmica e a estrutura da família nuclear e extensa. Diante dos desafios a serem enfrentados após o diagnóstico, cada sistema familiar cria suas próprias demandas e maneiras de lidar com o sofrimento. Os recursos emocionais destas resultam de um complexo entrecruzamento de fatores, tais como as crenças, os valores e a rede de apoio social e comunitária. Mais difícil é quando não se aceita a doença, partindo-se para idéias fantasiosas de que o indivíduo voltará a ser como era antes e de que não deve receber um tratamento especializado. Essa postura, além de dificultar o tratamento, pode desfavorecer a convivência com os portadores, aumentando o estresse e os conflitos.

\section{Principais atividades de cuidado e características} pessoais dos portadores de Alzheimer antes e após a doença, na perspectiva das filhas cuidadoras

Os cuidados desenvolvidos pelas filhas para com pais/ mães também puderam ser compreendidos pelos tipos de tarefas que exerciam. Notou-se que as atividades instrumentais foram mais apontadas do que as afetivas, sendo que a principal delas foi controlar/orientar. Atenta-se para o fato de que este papel atribuía-lhes uma posição na hierarquia - diferentes níveis de autoridade, ou seja, cada membro ocupa um nível de autoridade na família (Minuchin, 1982) - que geralmente era exercido por seus genitores antes da DA. Tal inversão hierárquica afetava a estrutura familiar, desencadeando sentimentos e ações conflituosas. Para ilustrar essa afirmação: "Eu senti como se fosse uma inversão de papéis, e isso foi horrível pra mim, pra família. Porque eu acho que filha não pode fazer mãe obedecer. Nem pode brigar com a mãe. Eu não me senti confortável neste papel de mãe dela. A minha mãe é a minha mãe, e eu não posso ser mãe dela. Eu não queria aceitar essa inversão de papéis" (Larissa).

É comum as filhas cuidadoras e familiares compararem o jeito de ser, as atitudes e os comportamentos que as mães/os pais enfermos tinham antes da doença com as ações posteriores. $\mathrm{Na}$ perspectiva das filhas entrevistadas, a principal característica do portador da DA, antes da doença, era de pessoa ativa e após a enfermidade passou a ser o fato de perder a memória e ficar desorientado(a). As lembranças de quem foi a mãe/o pai antes 
da enfermidade eram resgatadas por meio das várias histórias que compartilharam em família. O choro, aliado à sensação de perda gradativa da pessoa amada, amiúde acompanhavam o discurso. Várias delas mencionaram que tinham a impressão de que seus genitores haviam perdido as próprias identidades. Especialmente no início da doença, os comportamentos e traços de personalidade deles foram freqüentemente confundidos com os sintomas, desencadeando, por vezes, conflitos entre os familiares e os portadores.

É necessário reconhecer que os portadores de DA possuem uma estrutura de personalidade própria, e esta continua presente após a doença. Através dos discursos das cuidadoras, perceberam-se três aspectos que envolviam as características de personalidade destes sujeitos após o surgimento da demência: (a) em determinados casos, alguns traços marcantes da personalidade do paciente eram acentuados com a manifestação da doença, por exemplo, quem era autoritário passava a ser mais ainda; (b) em outros, não havia alterações consideráveis no jeito de ser do portador, por exemplo, quem era calmo permanecia assim; (c) nos demais casos, havia uma espécie de mudança de personalidade, por exemplo, quem era calmo passou a ser extremamente agressivo. Também, alguns apresentavam sintomas como alucinação e delírio, dificultando ainda mais para as filhas a compreensão de como lidar com os portadores. Conforme Leifer (2003), as alterações de personalidade são freqüentes nos pacientes com DA, apresentando, por vezes, sintomas psicóticos. A Organização Mundial de Saúde (1994) também destacou que a doença afeta cada pessoa de maneira diferente, e que o impacto dela na vida do paciente está relacionado às características pessoais anteriores a ela. Outrossim, é pertinente indagar até que ponto o portador da DA compreende o que está ocorrendo consigo.

Algumas filhas cuidadoras apontaram a existência de momentos em que seus pais/ suas mães demonstravam estar conscientes do que ocorria em suas vidas. Através dos relatos apresentados pelas cuidadoras, percebeu-se que, no início da doença, alguns pacientes tentavam justificar os lapsos de memória e disfarçar os erros cometidos, por meio de perguntas ou ações, durante a interação com outras pessoas. Possivelmente, diante dessas situações, eles estavam tendo noção do que ocorria em suas vidas. Na pesquisa realizada por Dourado, Laks, Rocha, Soares, Leibing e Engelhardt (2005) com 42 pacientes portadores de DA, foi visto que a consciência da doença estava preservada em $66,7 \%$ dos pacientes com estágio leve e $20,8 \%$ dos que estavam no estágio moderado, indicando uma perda progressiva da consciência da doença. Assim como o diagnóstico precoce, esses dados podem favorecer a comunicação entre profissionais, pacientes e familiares, bem como o planejamento de atividades de reabilitação e orientação familiar.

\section{Principais motivos para o exercício do papel de cuidadoras}

A essência do cuidar fundamenta-se na relação de obrigação, de gratidão e de responsabilidade pela pessoa que está dependente. Esses sentimentos perante os pais foram apresentados, por exemplo, por meio das verbalizações: "Eu acho que é uma obrigação cuidar dos pais idosos, e o carinho que ela sempre deu a todos nós justifica o compromisso que eu tenho com ela.” (Lia); “Ela já fez tanto por mim que hoje estou retribuindo” (Patrícia).

Notou-se que quando as cuidadoras se referiam ao seu dever, compromisso, gratidão ou obrigação de, como filhas, prestarem apoio aos seus pais, estavam remetendo a uma obrigação moral e ética determinada, expressa em uma regra de ação, que, nesse caso, é o cuidar. Segundo Boszormenyi-Nagy e Spark (1973/2003), os valores éticos se entrelaçam, do ponto de vista psicológico, com o "grande livro" da reciprocidade nas relações e com o compromisso que a pessoa assume diante desses vínculos. Os autores afirmaram que toda família mantém, no seu grande livro, uma contabilidade do que cada um dos seus membros pode esperar receber e do que deve dar. O patrimônio familiar herdado e, de essência, multigeracional, define, desde o nascimento, uma configuração específica de direitos e obrigações que se impõem ao indivíduo, que, para ser leal à família, deve se conformar. Assim, o grande livro diz respeito a uma contabilidade em dois planos: sempre que existe uma escritura contábil, existe, ao mesmo tempo, uma contrapartida em outra conta; a contabilidade do dia-a-dia é realizada em diários divisionários. Metaforicamente, descreve a natureza dos intercâmbios existentes entre um filho e seus pais ou, entre a família nuclear e a extensa.

Constatou-se que o dever de cuidar também está calcado nas ações impostas por normas socioculturais, econômicas e religiosas. No contexto tradicional das famílias brasileiras, é comum que os membros idosos sejam amparados por seus filhos (Aquino \& Cabral, 2002). Contudo, mais do que as pressões externas e a influência do meio, as "contas" éticas do "grande livro” parecem ter sido as principais determinantes das posturas adotadas pelas filhas, uma vez que seu efeito foi revelado durante as falas que assinalavam os compromissos interiorizados e exercidos através de suas ações.

Para relembrar, o conceito de legado proposto por Boszormenyi-Nagy e Spark (1973/2003) significa uma extensão transgeracional do princípio da delegação. O termo delegação, por sua vez, evoca uma ligação que estende, por meio de várias gerações, um compromisso ou uma obrigação de prestar contas. "O destino dos filhos se reflete como um espelho frente aos pais. A força reguladora crucial das relações familiares é o princípio de contabilização de responsabilidades e da possibilidade de confiança" (p. 40-41).

Todavia, faz-se mister apontar que os resultados obtidos nesta pesquisa não implicam dizer que necessariamente todas as filhas cuidadoras foram delegadas, escolhidas ou eleitas pelos pais e pelos membros da família a assumirem este papel. Nessa direção, apresentam-se alguns exemplos: “Eu não fui eleita pela minha mãe pra cuidar dela, eu cuido dela por falta de opção mesmo.” (Clara); "Não fui eleita pra cuidar do pai, assumi esse lugar por força das circunstâncias. Ele precisava de alguém e, talvez, dentre os filhos eu tenha sido a mais sensível ao problema. Cuido dele porque não suportei... não tive alternativa.” (Karina)

Cuidar dos enfermos familiares com Alzheimer, por falta de opção, também foi um resultado encontrado por Araújo (2001). Assim sendo, mais do que uma escolha, a necessidade 
de cuidar de uma pessoa idosa pode resultar de uma imposição circunstancial. Santos e Rifiotis (2003) sinalizaram que, em geral, a pessoa cuidadora não toma sozinha a decisão de cuidar. Esta se define na indisponibilidade de outros possíveis cuidadores, e quanto mais o cuidador se envolve, mais os não-cuidadores se desvencilham do cuidado. Esse tipo de dinâmica nunca ocorre de maneira tranqüila e linear, isto é, os relacionamentos interpessoais possuem conflitos associados às mudanças advindas com a evolução do processo demencial.

A assunção do papel de cuidadora não refletiu apenas os relacionamentos favoráveis que tinham antes da doença, mas, em alguns casos, revelaram os conflitos, as distâncias emocionais e geográficas entre eles. Assim, assumir esse papel era uma oportunidade de rever os erros do passado e resgatar os elos afetivos. Para Boszormenyi-Nagy e Spark (1973/2003), o desequilíbrio na reciprocidade de uma relação nunca é estático, nem permanece estancado.

É válido destacar que algumas filhas já exerciam o papel de cuidadoras mesmo antes da doença dos pais. A carreira de cuidados também foi encontrada em outras pesquisas (Silveira, 2003; Sommerhalder \& Neri, 2002). Neste estudo, a referida carreira, na família, estava freqüentemente associada à idéia de que somente elas sabiam cuidar dos enfermos. Assim, centralizavam as tarefas exercidas com os pacientes, não confiavam e nem desejavam que outros membros ocupassem esse lugar. Como ilustração, seguem os relatos: "Eu não confio muito que outra pessoa esteja com mamãe e esteja cuidando dela. Só eu que gosto de cuidar dela” (Cecília); "Sempre gostei de cuidar das pessoas. Quando era menina gostava de cuidar da minha avó. Depois fui ser professora e me envolvia com os problemas dos alunos e vivia pra eles. Sempre, na minha vida, tive que viver em função de alguém e nunca penso em mim. Eu não esqueço o remédio da minha mãe, mas, se for o meu, eu esqueço" (Beatriz).

Percebe-se que, além da carreira de cuidados, o discurso de Beatriz sugeriu que o exercício da função de cuidadora pode favorecer algum tipo de fuga, para evitar o contato consigo mesma, fato também encontrado na pesquisa de Luders e Storani (2005). O depoimento de Daniela complementou essa idéia: "Percebi que era conveniente pra mim, cuidar do meu pai. Precisava ter certas responsabilidades, pra não pensar nos meus problemas, nas coisas que não queria enfrentar. Então, preferi tomar as responsabilidades da família, pra não ter como pensar nas outras coisas. Hoje já penso que devo ter um tempo pra mim. Acho que todo mundo tem os seus demônios e eu preciso espantar e colocar os meus bem longe!"

Segundo Baker (1996), as experiências vivenciadas pelas filhas cuidadoras de pacientes com Alzheimer podem ser mais uma oportunidade de elas se compreenderem e realizarem uma auto-avaliação sobre suas vidas. Larissa também foi uma das filhas que mencionou essa mudança, após cuidar da mãe portadora de Alzheimer: "Eu acho que agora, depois de estar cuidando da minha mãe, sou mais humana. Antes, eu era um pouco revoltada. Eu achava que não precisava de ninguém. Acho que isso me fez crescer e mudar muito. A gente sofre, mas também é beneficiada. Meu relacionamento com todo mundo melhorou".
Por meio desses discursos, percebe-se que a atividade de cuidar vai além de uma obrigação moral e ética. Outrossim, ressalta-se que, nos grupos de apoio psicológico desenvolvidos no Centro de Referência do HUB, era discutida a importância de os cuidadores olharem para si e executarem atividades que lhes proporcionassem prazer. Notava-se que esse incentivo despertava a atenção para o fato de que, mesmo com a doença do familiar, a vida continuava. Essa visão aliviava um pouco a culpa que elas sentiam, quando não estavam olhando para seus enfermos, por estarem exercendo outras tarefas de seu interesse.

Nesta pesquisa, a queixa acerca da diminuição das atividades de lazer e da vida social era uma constante nos discursos das entrevistadas. Muitas filhas reclamavam da perda de liberdade, ao assumir a função de cuidadora. Segundo Santos e Rifiotis (2003), a vergonha e a evitação do convívio social mais amplo é comumente relatado pelas pessoas que cuidam de idosos demenciados. É constrangedor, por exemplo, avistar o portador despir-se em público, abordar, de maneira inesperada, pessoas desconhecidas na rua e não utilizar o banheiro para as suas necessidades fisiológicas. Também é crucial contextualizar as vivências destas mulheres na faixa etária a que pertencem. A maioria estava na meia-idade e se deparava com situações especiais em suas vidas, tais como o climatério e a aposentadoria. Destarte, enfrentavam mudanças de diversas ordens que sinalizavam a necessidade de serem ouvidas.

Voltando o olhar para as questões intrínsecas às razões que levaram as filhas a cuidarem de seus genitores, constatouse que as condições socioeconômicas e profissionais foram sinalizadas. Pode-se dizer que esse dado surgiu em decorrência do fato de que a maioria delas era aposentada, tendo condições de melhor assistir o idoso. Todavia, dentre as onze filhas que levantaram o nível socioeconômico como motivo, quatro não tinham emprego, e, ao invés de sustentarem financeiramente seus pais, duas eram sustentadas por eles e duas eram pagas pelos irmãos para exercerem a atividade de cuidado. O estado civil de solteira e o fato de nunca ter saído de casa também foram outros motivos apontados. A escolha de assumir a função, devido a esses fatores, veio acompanhada de questionamentos, revolta e insatisfação. Em cinco casos, os irmãos casados se sentiam livres da responsabilidade de cuidar de seus genitores, afirmando que tinham suas famílias atuais para cuidar, ou porque havia conflitos entre os membros destas e suas famílias de origem.

A posição dos irmãos, conceito desenvolvido por Bowen (1978), levou a se investigar, nesta pesquisa, se a posição ocupada pelas cuidadoras estava relacionada com o papel exercido na família. Chamou a atenção o fato de que, dentre as 32 filhas investigadas, 13 eram as mais velhas e 8 eram as mais novas do sistema familiar nuclear. Apesar de a maioria não ter explicitado esse fator como motivo para cuidar dos portadores, tais dados permitem refletir sobre a possibilidade da existência de normas sociais, valores culturais, legados e regras de algumas famílias. Para Minuchin e Fishman (2003), no grupo dos irmãos, por ser o primeiro grupo de companheiros do indivíduo, são desenvolvidos os padrões para negociação, cooperação, competição e obtenção de reconhecimento.

Num estudo sobre os primogênitos, Perez (2002) destacou que estes são os que possuem acesso exclusivo ao casal parental 
por um período indeterminado de tempo. Desse modo, recebem uma atenção maior dos pais, identificam-se com questões de autoridade e formas mais conservadoras de comportamentos e normas sociais. Por sua vez, os pais depositam mais expectativas em relação a eles, especialmente, nas mulheres, que exercem mais o papel de cuidadoras, orientadoras e intermediárias entre os irmãos e seus genitores.

Outro motivo apontado por duas cuidadoras para exercerem esta função foi o fato de possuírem características de personalidade que, na percepção delas, favoreciam a assunção desse papel, dado obtido em outras pesquisas (Neri \& Sommerhalder, 2002; Santos, 2003). Verificou-se, também, que a "missão divina" foi uma das razões apontadas por elas para desempenharem essa função. Esse dado também foi encontrado no estudo de Silveira (2003).

A religiosidade atua como um mediador na percepção de ônus e benefício do papel de cuidar, uma vez que a fé e os preceitos religiosos favorecem a capacidade de superar os sentimentos negativos (Sommerhalder \& Neri, 2002). Nesse cenário, é fundamental pensar além dos sentimentos de obrigação filial, de gratidão e de amor que estas cuidadoras nutriam por seus genitores, refletindo sobre como eram os relacionamentos entre tais figuras antes da doença, como ficaram depois da mesma, e como elas se sentiam exercendo o papel.

\section{Os sentimentos das filhas de pais/mães com DA dian- te do papel de cuidar}

As relações das filhas cuidadoras com seus genitores portadores de DA eram marcadas por dilemas tais como satisfação e estresse, acúmulo de experiência e sensação de perda. Todavia, a análise de conteúdo das entrevistas revelou que as verbalizações mais destacadas por elas giravam em torno do sentimento desfavorável diante do fato de cuidar dos genitores.

No tópico anterior, destacou-se que o motivo mais apontado pelas cuidadoras para exercerem este papel foi o sentimento de obrigação filial. Entrementes, percebeu-se que, apesar de a maioria delas se achar na obrigação de cuidar, não se sentia bem executando essa tarefa, fato que corroborou o resultado da pesquisa de Neufeld e Harrison (1998). Estes autores verificaram que as pessoas que desenvolviam o cuidado por obrigação eram mais acometidas por sentimentos negativos do que aquelas que o faziam com prazer. Também, no estudo realizado por Araújo (2003), constatou-se que o sentimento diante do exercício de cuidar desenvolvido pelas cuidadoras familiares foi predominantemente negativo, propiciando discussões na família e insatisfação pessoal.

Sobre esse tema, apresentam-se alguns relatos: "Pra ser absolutamente franca? Eu sinto como se ela fosse um estorvo na minha vida!” (Clara); “Uma vez, a psicóloga me perguntou como eu compreendia a questão da morte, e eu disse pra ela que eu não falo da morte da minha mãe. Eu acho que quem está realmente morrendo sou eu. [chora]" (Sâmia); "Só de ver o sofrimento dela, sofro. Às vezes, eu sou obrigada a deixar ela trancada dentro do quarto, pra poder dormir. Um dia, abri a porta e, ela estava no chão. Aquilo me cortou o coração. Ela tava gemendo e toda gelada [chora]" (Alice).

Os sofrimentos vivenciados mais relatados pelas filhas cuidadoras foram estresse, depressão, sentimento de culpa, isolamento e raiva. Tais dados se assemelham aos achados de outros pesquisadores (Teel \& Carson, 2003; Winslow, 2003). Elas também tenderam a verbalizar que, antes da doença dos portadores, suas vidas pessoais tinham aspectos desfavoráveis à saúde física e emocional, tornando-se mais acentuados após a demência.

Percebe-se que a atividade de cuidar é heterogênea, e as avaliações subjetivas são amplamente influenciadas por crenças, prioridades e valores, pelo relacionamento passado e atual com o idoso e por suas percepções acerca da velhice e do cuidado. Alguns fatores podem atuar como amortecedores entre as pressões externas e os sentimentos diante do ato de cuidar, a saber: a ajuda instrumental e emocional oferecida por redes formais e informais de apoio, os conhecimentos e habilidades de quem cuida, bem como as estratégias de enfrentamento que utilizam. É preciso considerar que os fatores positivos e negativos diante da atividade de cuidar também funcionam como parâmetros, na avaliação da dinâmica dos cuidados, abarcando seus aspectos multidimensionais (Neri \& Sommerhalder, 2002).

\section{Considerações finais}

A maioria da população ainda se encontra sem as informações nem o apoio necessário de assistência às doenças como a demência, sendo crucial enfatizar o ensino e a prática da saúde preventiva. Nos programas de intervenção voltados para portadores, cuidadores e familiares, devem ser levadas em consideração as questões de gênero e as relações intergeracionais. Reuniões específicas para filhas cuidadoras, por exemplo, favorecem a compreensão e o relacionamento com seus pais, podendo amenizar o estresse vivenciado na família (Barber \& Pasley, 1995). Os homens que exercem o papel de cuidadores também merecem atenção em outras pesquisas. Face à complexidade e à relevância do tema abordado são necessários outros estudos que investiguem, por exemplo, as relações familiares de portadores da DA, favorecendo a criação e execução de políticas públicas que propiciem intervenções eficazes na promoção de saúde das pessoas envolvidas com a temática em pauta.

\section{Agradecimentos}

As autoras agradecem o apoio da CAPES.

\section{Referências}

Aquino, T. M. A., \& Cabral, B. E. S. (2002). O idoso e a família. In E. V. Freitas, L. Py, A. L. Neri, F. A. X. Cançado, M. L. Gorzoni, \& S. M. Rocha (Orgs.), Tratado de geriatria e gerontologia (pp. 1056-1060). Rio de Janeiro: Guanabara.

Araújo, A. R. (2003). Cuidador familiar de idosos: uma abordagem compreensiva. Dissertação de mestrado não-publicada, Universidade Federal do Ceará, Fortaleza.

Araújo, P. B. (2001). Alzheimer: o idoso, a família e as relações humanas. Rio de Janeiro: O Autor. 
Baker, L. K. (1996). “She doesn’t even know me any more”: Alzheimer’s disease tests the bond between mothers and daughters. Ladies Home Journal, 113(7), 52-54.

Barber, C. E., \& Pasley, B. K. (1995). Family care of Alzheimer's patients: the role of gender and generational relationship on caregiver outcomes. Journal of Applied Gerontology, 14(2), 172-121.

Bardin, L. (2000). Análise de conteúdo. Lisboa: Edições 70. (Original publicado em 1977)

Boszormenyi-Nagy, I., \& Spark, G. (2003). Lealtades invisibles: reciprocidad en terapia familiar intergeracional. Buenos Aires: Amorrotu. (Original publicado em 1973)

Bowen, M. (1978). Family therapy in clinical practice. Nova York: Jason Aronson.

Caramelli, P., \& Barbosa, M. T. (2002). Como diagnosticar as quatro causas mais freqüentes de demência? Revista Brasileira de Psiquiatria, 24(SI), 7-10.

Cattani R. B., \& Girardon-Perlini, N. M. O. (2004). Cuidar do idoso doente no domicílio na voz de cuidadores familiares. Revista Eletrônica de Enfermagem, 6(2), 254-271.

Charchat, H., Nitrini, R., Caramelli, P., \& Sameshima, K. (2001). Investigação de marcadores clínicos dos estágios iniciais da doença de Alzheimer com testes neuropsicológicos computadorizados. Psicologia Reflexão e Crítica, 14(2), 305-316.

Coelho, V. L. D., \& Diniz, G. R. S. (2005). Da solidão à solidariedade: grupos de familiares de idosos com demência. In T. Féres-Carneiro (Org.), Família e casal: efeitos da contemporaneidade (pp. 177-199). Rio de Janeiro: Editora da Pontifícia Universidade Católica.

Coelho, V. L. D., Falcão, D. V. S., Campos, A. P. M., \& Vieira, M. F. T. (2006). Atendimento psicológico grupal a familiares de idosos com demência. In D. V. S. Falcão \& C. M. S. B. Dias (Orgs.), Maturidade e velhice: pesquisas e intervenções psicológicas (pp. 81-103). São Paulo: Casa do Psicólogo.

Coen, R. F., Swanwick, G. R., O’Boyle, C. A., \& Coakley, D. (1997). Behaviour disturbance and other predictors of career burden in Alzheimer's disease. Journal of Geriatric Psychiatry, 12(3), 331-336.

Dourado, M., Laks, J., Rocha, M., Leibing, A., \& Engelhardt, E. (2005). Consciência da doença na demência: resultados preliminares em pacientes com Alzheimer leve e moderada. Arquivos de Neuro-Psiquiatria, 6(1), 114-118.

Falcão, D. V. S. (2006). Doença de Alzheimer: um estudo sobre o papel das filhas cuidadoras e suas relações familiares. Tese de doutorado não-publicada, Universidade de Brasília, Brasília.

Lechner, V., \& Neal, M. (1999). The mix of public and private programs in the United States: implications for employed caregivers. In S. V. Lechner \& M. Neal, (Orgs.), Work and caring for the elderly: international perspectives (pp. 120-137). Philadelphia: Taylor \& Francis.

Leifer, B. P. (2003). Early diagnosis of Alzheimer's disease: clinical and economic benefits. Journal of Geriatrics Society, 51(S5), 281-288.
Luders, S. L. A., \& Storani, M. S. B. (2005). Demência: impacto para a família e a sociedade. In M. P. Netto (Org.), Gerontologia: a velhice e o envelhecimento em visão globalizada (pp. 146-159). São Paulo: Atheneu.

Ministério da Saúde (2008). Guia prático do cuidador. Brasília: Autor.

Minuchin, S. (1982). Família: funcionamento e tratamento. Porto Alegre: Artes Médicas.

Minuchin, S., \& Fishman, C. H. (2003). Family healing: strategies for hope and understanding. Nova York: Simon \& Schuster.

Neri, A. L., \& Sommerhalder, C. (2002). As várias faces do cuidado e do bem-estar do cuidador. In A. L. Neri (Org.), Cuidar de idosos no contexto da família: questões psicológicas e sociais (pp. 9-63). Campinas: Alínea.

Neufeld, A., \& Harrison, M. J. (1998). Men as caregivers: reciprocal relationships or obligation? Journal of Advanced Nursing, 28(5), 959-968.

Organização Mundial de Saúde. (1994). Ayuda para cuidadores de personas con demencia. Geneva: Autor (Department of Social Change and Mental Health).

Perez, A. F. (2002). O filho primogênito. In A. Wagner (Org.), Família em cena: tramas, dramas e transformações (pp. 113-131). Petrópolis: Vozes.

Robinson, K. M., Adkisson, P., \& Weinrich, S. (2001). Problem behaviour, caregiver reactions, and impact among caregivers of persons with Alzheimer Disease. Journal of Advanced Nursing, 36(4), 573-582.

Santos, S. M. A. (2003). Idosos, família e cultura: um estudo sobre a construção do papel do cuidador. Campinas: Alínea.

Santos, S. M. A., \& Rifiotis, T. (2003). Cuidadores familiares de idosos dementados: uma reflexão sobre e o cuidado e o papel dos conflitos na dinâmica da família cuidadora. In O. R. M. V. Simson, A. L. Neri, \& M. Cachioni (Orgs.), As múltiplas faces da velhice no Brasil (pp. 141-164). Campinas, SP: Alínea.

Sawatzky, J. E., \& Fowler-Kerry, S. (2003). Impact of caregiving: listening to the voice of informal caregivers. Journal of Psychiatric and Mental Health Nursing, 10, 277-286.

Silveira, T. M. (2003). “Fomos escolhidos”: um estudo sobre cuidadores familiares principais. Tese de doutorado não-publicada, Pontifícia Universidade Católica do Rio de Janeiro, Rio de Janeiro.

Sociedad Española de Geriatría y Gerontología (2005). ¿Quienes son los cuidadores de personas mayores dependientes? Obtida em 17 de dezembro de 2007, de http://www.segg.es/segg/html/cuidadores/cuidador/quienes_son. htm\#

Sommerhalder, C., \& Neri, A. L. (2002). Avaliação subjetiva da tarefa de cuidar: ônus e benefícios percebidos por cuidadoras familiares de idosos de alta dependência. In A. L. Neri (Org.), Cuidar de idosos no contexto da família: questões psicológicas e sociais (pp. 93-134). Campinas: Alínea.

Teel, C., \& Carson, P. (2003). Family experiences in the journey through dementia diagnosis and care. Journal of Family Nursing, 9, 38-58.

Winslow, B. W. (2003). Family caregivers' experiences with community services: a qualitative analysis. Public Health Nursing, 20(5), 341-348. 
Deusivania Vieira da Silva Falcão, doutora em Psicologia pela Universidade de Brasília, é professora da Escola de Artes, Ciências e Humanidades da Universidade de São Paulo. Endereço para correspondência: Av. Arlindo Béttio, 1000 (Ermelino Matarazzo); USP - EACH; São Paulo, SP; CEP: 03828-000. E-mail: deusivania@usp.br

Julia Sursis Nobre Ferro Bucher-Maluschke, pós-doutora pela Universität Tübingen -Alemanha e pela St. Jonh’s University - Estados Unidos, é professora emérita e pesquisadora associada sênior do Programa de Pós-Graduação em Psicologia Clínica da Universidade de Brasília e Professora Titular do Programa de PósGraduação em Psicologia da Universidade de Fortaleza. E-mail: juliasursis@gmail.com 


\section{Apêndice}

\begin{tabular}{|c|c|}
\hline Categorias, códigos, definições & $\begin{array}{l}\text { Subcategorias, códigos, exemplos de } \\
\text { trechos extraídos das entrevistas }\end{array}$ \\
\hline $\begin{array}{l}\text { Categoria 1: Reação inicial das filhas cuidadoras e } \\
\text { de seus familiares diante da descoberta do provável/ } \\
\text { possível diagnóstico da doença de Alzheimer dos pais/ } \\
\text { das mães (Código: RIFDA). } \\
\text { Definição: nesta categoria estão presentes os conte- } \\
\text { údos das falas relativas às reações iniciais das filhas } \\
\text { cuidadoras diante da descoberta do provável/possível } \\
\text { diagnóstico da DA. }\end{array}$ & $\begin{array}{l}\text { a) Reação inicial favorável à utilização dos recursos da família } \\
\text { para lidar com a doença (Código: RIF). Ex.: "Eu e minha famí- } \\
\text { lia reagimos legal ao receber a notícia da doença.” (Lorena) } \\
\text { b) Reação inicial desfavorável à utilização dos recursos da } \\
\text { família para lidar com a doença (CRID). } \\
\text { Ex.: "Eu fiquei muito preocupada. Não quis aceitar. Essa doen- } \\
\text { ça é muito triste!” (Marta) } \\
\text { c) Reação inicial neutra à utilização dos recursos da família } \\
\text { para lidar com a doença (RIN). } \\
\text { Ex.: "A princípio, eu e minha família não tivemos nenhuma } \\
\text { reação." (Giovana) }\end{array}$ \\
\hline $\begin{array}{l}\text { Categoria 2: Principais atividades de cuidado com } \\
\text { as mães/os pais portadores da doença de Alzheimer } \\
\text { desenvolvidas pelas filhas cuidadoras (PADFCA). } \\
\text { Nesta categoria, estão presentes os conteúdos ine- } \\
\text { rentes às atividades desenvolvidas pelas filhas nos } \\
\text { cuidados com os pais/as mães portadores da DA. }\end{array}$ & $\begin{array}{l}\text { - Atividades Instrumentais (AI): } \\
\text { a) Controlar/Orientar (CO). Ex.: "Procuro manter o controle de } \\
\text { tudo. Hora de comer, tomar sol.” (Ana) } \\
\text { b) Cuidar da Higiene Pessoal (CHP). Ex.: "Cuido de toda a } \\
\text { higiene pessoal dele.” (Isabela) } \\
\text { c) Cuidar da Alimentação e da Medicação (CAM). Ex.: "Dou } \\
\text { os remédios e a alimentação dela.” (Lívia) } \\
\text { d) Passear/Realizar Caminhadas (PC). Ex.: "Faço caminhadas } \\
\text { com ele todos os dias na praça...” (Vilma). } \\
\text { e) Levar ao médico (LM). Ex.: "Eu sempre estou levando ela } \\
\text { pro médico.” (Liduína) } \\
\text { - Atividades Afetivas (AA): } \\
\text { f) Conversar (C). Ex.: "Eu procuro sempre conversar.” (Bruna) } \\
\text { g) Dar carinho (DC). Ex.: "Tento passar pra ela o máximo de } \\
\text { carinho.” (Luana) }\end{array}$ \\
\hline $\begin{array}{l}\text { Categoria 3: Principais características pessoais dos } \\
\text { pais/das mães portadores da DA, antes e após a doen- } \\
\text { ça, na perspectiva das filhas cuidadoras (PCPIDA). } \\
\text { Nesta categoria, encontram-se os conteúdos das falas } \\
\text { das participantes acerca das principais características } \\
\text { pessoais dos portadores da DA antes e após a doença. }\end{array}$ & $\begin{array}{l}\text { - Antes da Doença de Alzheimer (AnDA): } \\
\text { a) Pessoa ativa (PAT). Ex.: “A mamãe era uma mulher ativa, } \\
\text { trabalhadora...” (Beatriz) } \\
\text { b) Pessoa dominadora (PD). Ex.: "Ele era dominador e estava } \\
\text { sempre com a razão!” (Simone) } \\
\text { c) Amoroso(a)/Prestativo(a) (AP). Ex.: "Ela era uma pessoa } \\
\text { amorosa e sempre prestativa...” (Talita) } \\
\text { d) Estressado(a)/Explosivo(a) (EE). Ex.: “O papai... ele era } \\
\text { ansioso, preocupado, insatisfeito, não dormia bem, trabalhava } \\
\text { até tarde, vivia estressado.” (Daniela) } \\
\text { e) Quieto(a)/Calmo(a) (QC). Ex.: "Papai sempre foi calmo. } \\
\text { Resolvia as coisas de forma serena.” (Ana) } \\
\text { - Após a Doença de Alzheimer (ApDA): } \\
\text { a) Perdeu a memória (PM). Ex.: “Ela não sabe quem sou eu, } \\
\text { quem são meus irmãos.” (Carol) } \\
\text { b) Desorientado(a) (D). Ex.: “Se ela vê água sanitária, ela quer } \\
\text { beber. Faz cocô no chão...” (Lorena) } \\
\text { c) Perdeu a autonomia (PA). Ex.: "Ela não está conseguindo } \\
\text { resolver as coisas por ela mesma.” (Sueli) }\end{array}$ \\
\hline
\end{tabular}




\begin{tabular}{|c|c|}
\hline & $\begin{array}{l}\text { d) Inquieto(a)/caminha compulsivamente (IC). Ex.: “Passou a } \\
\text { noite toda andando pela casa.” (Gisele) } \\
\text { e) Agressivo(a) (verbalmente/fisicamente) (A). Ex.: “Ela } \\
\text { agride, quer bater, puxar o cabelo!” (Clara) } \\
\text { f) Apresenta falas repetitivas e dificuldade na comunicação } \\
\text { (AFRDC). Ex.: “Todo dia ele diz assim: 'eu gosto de sair } \\
\text { com você!' E fica falando o tempo todo a mesma coisa. É um } \\
\text { problema.” (Isabela) } \\
\text { g) Alucinando/Delirando (AD). Ex.: “Ela vê coisas que não } \\
\text { existem e começou com a idéia de que a família do vizinho } \\
\text { queria matá-la.” (Beatriz) } \\
\text { h) Implicante (Ip). Ex.: "Ela tem essa implicância com essa } \\
\text { minha neta e com a minha filha.” (Luana) } \\
\text { i) Apresenta picos de lucidez (PL). Ex.: “Às vezes ela tem } \\
\text { momentos de lucidez.” (Débora). } \\
\text { j) Apresenta labilidade emocional (PLE). Ex.: “Às vezes, ela } \\
\text { sorri e, daqui a pouco, chora.” (Cecília) }\end{array}$ \\
\hline $\begin{array}{l}\text { Categoria 4: Sentimento das filhas cuidadoras diante do } \\
\text { fato de cuidar das mães/dos pais portadores da doença de } \\
\text { Alzheimer (SFCPMPA). } \\
\text { Nesta categoria estão presentes os conteúdos relativos } \\
\text { aos sentimentos das filhas cuidadoras diante do fato de } \\
\text { cuidar do(a)s pais/mães portadores da DA. }\end{array}$ & $\begin{array}{l}\text { a) Sentimento favorável (SF). Ex.: “Cuido dela porque é um } \\
\text { prazer que eu sinto nisso.” (Débora) } \\
\text { b) Sentimento desfavorável (SD). Ex.: "Estou cansada... eu me } \\
\text { sinto muito sugada por ela.” (Clara) } \\
\text { c) Sentimento neutro (SN). Ex.: "Não me sinto nem bem nem } \\
\text { mal, cuidando dele. É normal.” (Joyce) }\end{array}$ \\
\hline $\begin{array}{l}\text { Categoria 5: Vida pessoal das filhas cuidadoras antes } \\
\text { e após a doença das mães/dos pais portadores da DA } \\
\text { (VPCAPDA). } \\
\text { Nesta categoria, encontram-se os conteúdos sobre a vida } \\
\text { pessoal das filhas cuidadoras antes e após a doença das } \\
\text { mães/dos pais portadores da DA. }\end{array}$ & $\begin{array}{l}\text { - Vida Pessoal Antes da Doença de Alzheimer (ViAnDA): } \\
\text { a) Vida pessoal com aspectos favoráveis à rotina antes da } \\
\text { doença (VPFAD). Ex.: "Antes da doença da mamãe eu não } \\
\text { tinha grandes problemas. Além de tudo tinha mais liberdade.” } \\
\text { (Gabriela) } \\
\text { b) Vida pessoal com aspectos desfavoráveis à rotina antes da } \\
\text { doença (VPDAD). Ex.: "Olha, a minha vida, antes da doença } \\
\text { dela já tinha virado de cabeça pra baixo! Já era um caos.” } \\
\text { (Diana) } \\
\text { c) Vida pessoal com aspectos neutros antes da doença (VP- } \\
\text { NAD). Ex.: "Eu levava uma vida normal.” (Lia) } \\
\text { - Vida Pessoal Após a Doença de Alzheimer (ViApDA): } \\
\text { a) Vida pessoal com aspectos favoráveis à rotina após a doença } \\
\text { (VPFAAPD). Ex.: "A experiência de cuidar da mamãe me fez } \\
\text { mudar muito! Hoje eu sou mais compreensiva e mais amiga...” } \\
\text { (Alessandra) } \\
\text { b) Vida pessoal com aspectos desfavoráveis à rotina após a } \\
\text { doença (VPDAAPD). Ex.: "Depois da doença dela, fico o } \\
\text { tempo todo me enchendo de dívida. Estou debilitada, com } \\
\text { anemia, desânimo...” (Lívia) } \\
\text { c) Vida pessoal com aspectos neutros após a doença (VPNA- } \\
\text { AD). Ex.: "Vejo que tudo isso que vem acontecendo comigo } \\
\text { após a doença da mamãe, é natural, minha vida segue um } \\
\text { curso normal.” (Carolina) }\end{array}$ \\
\hline
\end{tabular}

